Revista Brasileira de Agricultura Irrigada v.10, nº.4, p. 799- 808, 2016

ISSN 1982-7679 (On-line)

Fortaleza, CE, INOVAGRI - http://www.inovagri.org.br

DOI: $10.7127 /$ rbai.v10n400445

Protocolo 445.16 - 28/06/2016 Aprovado em 12/08/2016

\title{
AVALIAÇÃO DOS NÍVEIS DE LÂMINA DE IRRIGAÇÃO NO DESEMPENHO DO FEIJOEIRO CULTIVADO NA REGIÃO DA ZONA DA MATA, MG
}

\author{
Monalisa Soares Costa $^{1}$, Everardo Chartuni Mantovani ${ }^{2}$, Fernando França da Cunha ${ }^{3}$, \\ Catariny Cabral Aleman ${ }^{3}$
}

\begin{abstract}
RESUMO
O cultivo de feijão é tradicional ao produtor brasileiro, principalmente para os pequenos e médios produtores. No plantio, as altas produtividades se devem em parte à irrigação, que para ser feita de maneira sustentável tem que ser acompanhada de um manejo. Objetivou-se estudar nesse trabalho o comportamento da cultivar de feijoeiro "Ouro Vermelho" a vários níveis de irrigação durante o período sem ocorrência de chuva frequente. Foram testados quatro níveis de irrigação de acordo com uma metodologia de cálculo de lâmina utilizada para o manejo de irrigação, variando em 30\%, 80\%, 100\% e 145\% da quantidade recomendada por este método. A irrigação foi feita através de um pivô central convencional. A área experimental era plana, uniforme e não apresentava problemas de salinidade do solo e da água, e ocorrência de ataque de doenças ao longo do experimento. A ausência do ajuste quadrático em relação às lâminas de irrigação não permitiu a definição de um ponto ótimo para a produção final de grãos e biomassa, sendo quanto maior a lâmina maior o desempenho da cultura. O índice de aproveitamento da água evapotranspirada pela planta foi proporcional à sua produtividade nos níveis de lâmina aplicados. Conclui-se que as lâminas de irrigação apresentaram efeito crescente no rendimento da cultura no campo.
\end{abstract}

Palavras-chave: agricultura irrigada, produção agrícola, disponibilidade hídrica.

\section{MANAGEMENT WATER ON YIELD CROP BEAN PLANTED IN ZONA DA MATA, MG}

\footnotetext{
ABSTRACT

The planting of crop bean is traditional Brazilian farmers, mainly for the small and medium farmers. On planting, the high yield it gives for irrigation and another factor, for to do the first

${ }^{1}$ Eng. Agrônomo, Mestre em Engenharia Agrícola, Doutoranda em Engenharia Agrícola na Universidade Federal Rural de Pernambuco, Recife, Pernambuco, Brasil, e-mail: monalisa_sc@hotmail.com

${ }^{2}$ Eng. Agrícola, Professor Titular na Universidade Federal de Viçosa, Viçosa, Minas Gerais, Brasil, e-mail: Everardo@ufv.br

${ }^{3}$ Agrônomo, Professor Adjunto na Universidade Federal de Viçosa, Viçosa, Minas Gerais, Brasil, e-mail: catariny@ufv.br, fernando.franca@ufv.br
} 
one in a way sustainable way have to be together a management of depth irrigation. The aim of this study is the behavior of "Red Bean" crop bean cultivar for different levels of depth irrigation. Were tested four levels of depth irrigation that was calculated with a method of determination of depth irrigation and used on an irrigation management, raging in $30 \%, 80 \%$, $100 \%$ and $145 \%$ of the crop evapotranspiration calculated. The irrigation was made through a sprinkle system with a central pivot. The experimental field was plan, uniform and don't have problems of soil and water salinity, and wasn't observed disease occurrence. The no observation of quadratic behavior of the depth irrigation and production and biomass didn't allow the obtainment of great depth irrigation, been how much taller the depth irrigation, better the yield. The index evapotranspired water productivity was proportional to productivity through depth irrigation levels. In conclusion, the depth irrigation presented effect on crop yield.

Keywords: agricultural irrigation, crop production, water availability

\section{INTRODUÇÃO}

O feijão é um grão de consumo tradicional em todo Brasil, sendo amplamente cultivado, principalmente por pequenos e médios produtores. É constituído principalmente de base proteica, base energética, carboidratos e minerais. Dentre esses, se destaca o mineral ferro, que é encontrado em maior concentração (BORÉM; CARNEIRO, 2015).

A sua produção no país no ano de 2014 foi de 3,2 milhões de toneladas de grãos, com uma expectativa de redução de $1,5 \%$ da área cultivada e aumento da produtividade de 3,4\% no ano de 2015. Os principais estados produtores são Paraná (23,1\% da produção nacional), Minas Gerais (16,1\%) e Bahia (9,9\%) (IBGE, 2015).

O feijoeiro é cultivado em diferentes épocas do ano, garantindo abastecimento constante no mercado ao longo do ano. Em épocas de plantio como primavera-verão e verão-outono, normalmente não se utiliza irrigação devido a predominância de ocorrência de chuvas. Já em períodos como outono-inverno e inverno-primavera, a irrigação é necessária, e normalmente feita com sistema de aspersão convencional, por quem possui a tecnologia (VIEIRA, 2004).

É uma cultura em que pouco se utiliza irrigação no plantio, normalmente é cultivada de modo sequeiro. Mas o suprimento hídrico regular contribui para elevadas produtividades, explorando mais o potencial produtivo da planta (REZENDE et al., 2004).
A irrigação é um fator essencial para um bom desempenho da cultura no campo, principalmente quando cultivada em um período de difícil ocorrência de chuvas. Quando bem manejada faz com que a planta consiga expressar melhor o seu potencial produtivo, além de balancear a questão ambiental, envolvendo a sustentabilidade, quando o assunto é escassez de recursos hídricos (BERNARDO et al., 2006).

De acordo com o boletim da FAO (ALEXANDRATOS; BRUINSMA, 2012), a irrigação nos próximos anos tende a assumir um papel mais significativo nas áreas de produção, visto que há previsão das áreas irrigadas passarem por uma expansão, com expectativa de produzir mais em uma mesma quantidade de terra cultivada, a fim de suprir a demanda mundial de alimentos que aumenta progressivamente, e também de atender áreas de poucos recursos e com difícil acesso.

No entanto, ao mesmo tempo, é importante a reprodução de um regime de estresse hídrico, sob o ponto de vista de conhecimento do comportamento da cultivar sob determinadas condições, observando se essa possui resistência, mantendo uma boa produtividade, ou, caso contrário, produzindo menos, e também visto a reduzida disponibilidade de água potável atual.

O objetivo do trabalho foi avaliar a produtividade de grãos do feijoeiro, cultivar “Ouro Vermelho”, em função da variação da disponibilidade hídrica para a cultura. 


\section{MATERIAL E MÉTODOS}

O experimento foi realizado entre os meses de julho e outubro de 2015, na área experimental da Universidade Federal de Viçosa, no município de Coimbra - MG, situada na zona da mata de Minas Gerais, nas coordenadas geográficas $20^{\circ} 45^{\prime} \mathrm{S} 42^{\circ} 5^{\prime}$ ' W, 698 m de altitude. Segundo a classificação de Köpen, o clima é do tipo Cwb, mesotérmico, com verões chuvosos e invernos frios e secos.

O tipo de solo foi classificado como Argissolo Vermelho Amarelo Distrófico, fase terraço, com textura argilosa (ANDRADE et al., 2005).

A cultivar de feijoeiro utilizada foi a Ouro Vermelho e a semeadura foi realizada utilizando 14 sementes por metro, com espaçamento entre linhas de $0,5 \mathrm{~m}$.

A irrigação de referência foi obtida por meio da equação de evapotranspiração de referência $\left(\mathrm{ET}_{0}\right)$ de acordo com a equação proposta por Allen et al. (1998), e evapotranspiração da cultura $\left(\mathrm{ET}_{\mathrm{c}}\right)$ conforme Bernardo et al. (2006).

Foram aplicados quatro níveis de irrigação: $30, \quad 80,100$ e $145 \%$ da necessidade de lâmina de irrigação calculada, de maneira a reproduzir um estresse hídrico com níveis severo de falta de água e de excesso, para posteriormente analisar o comportamento da cultivar de feijão Ouro Vermelho à essas mudanças no regime hídrico. Esses níveis proporcionam lâminas de irrigação totais (irrigação + precipitação efetiva) de 239, 309, 322 e $386 \mathrm{~mm}$, respectivamente.

Os coeficientes de cultivo (Kc) para as fases de germinação/emergência, reprodução e senescência/maturação dos grãos foram de 0,5 , 1,15 e 0,3, respectivamente (ALLEN et al., 1998). O coeficiente de estresse hídrico (Ks) foi obtido por meio da metodologia de Pierce (BERNARDO et al., 2006). O coeficiente de molhamento $(\mathrm{Kl})$ foi igual a unidade, pois a irrigação foi realizada através do sistema de aspersão convencional, molhando 100\% da área.
O solo em que foi feito o experimento possui teores de água equivalentes a umidade de capacidade de campo e ponto de murcha de $34 \%$ e $18 \%$ (em base de massa), respectivamente; e densidade do solo de $1,28 \mathrm{~g} \mathrm{~cm}^{-3}$. Adotou-se um fator de disponibilidade hídrica de 0,5 . O solo e a água utilizados não apresentavam problemas de salinidade. Esse primeiro possuía uma condutividade elétrica de $0,058 \mathrm{dS} \mathrm{m}^{-1}$ e $\mathrm{pH}$ de 5,04 .

O solo do estudo apresenta a seguinte curva de retenção de água (Figura 1) e a equação proposta por van Genuchten (1980) com seus parâmetros ajustados (Equação 1).

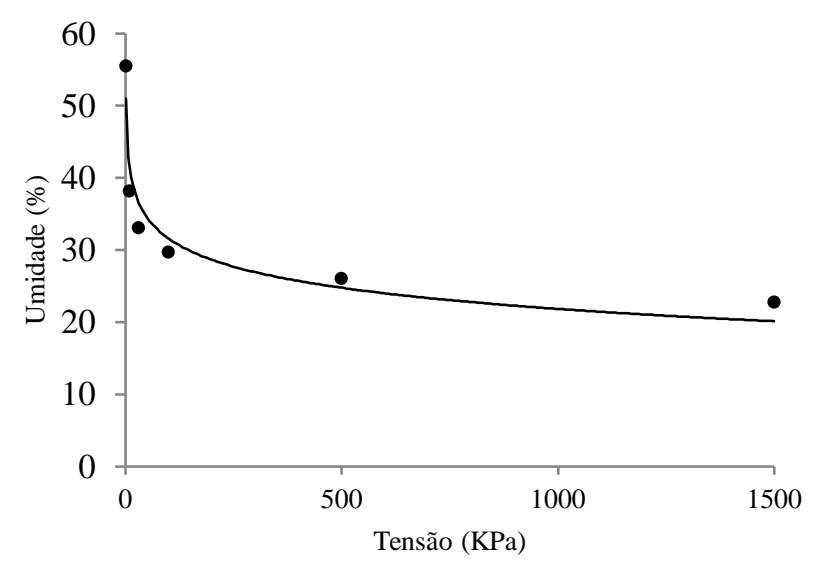

Figura 1. Curva de retenção de água do solo em que foi feito o estudo.

$$
\theta=0,228+\frac{(0,555-0,228)}{\left[1+\left(0,55 \cdot\left|\Psi_{m}\right|^{9,69}\right)\right]^{0,045}}
$$

Em que:

$\Theta$ : umidade, em $\mathrm{cm}^{3} \mathrm{~cm}^{-3} ; \Psi:$ potencial matricial, em KPa.

As lâminas foram calculadas com base em dados de uma estação agrometeorológica instalada próximo à área de cultivo que registra e afere a cada hora a temperatura máxima $\left({ }^{\circ} \mathrm{C}\right)$, mínima $\left({ }^{\circ} \mathrm{C}\right)$ e média $\left({ }^{\circ} \mathrm{C}\right)$, velocidade do vento $\left(\mathrm{m} \mathrm{s}^{-1}\right)$, umidade relativa do ar média (\%), radiação solar ( $\left.\mathrm{W} \mathrm{m}^{-2}\right)$ e precipitação $(\mathrm{mm})$.

Após a colheita determinou-se a produtividade (Prod) através da obtenção da produção de grãos da parcela e transformada em $\mathrm{kg} \mathrm{ha}^{-1}$; o número de grãos por vagem (NSV), em que foi feito amostragem de um determinado 
número de vagens aleatoriamente, contabilizado o número de sementes e dividindo pelo número de vagens; número de vagens por planta (NVP), em que foram contabilizadas as vagens das plantas colhidas de uma das linhas de semeadura, sempre a linha central, e dividida pelo número de plantas utilizadas; massa de 100 grãos (M100), em que se tomou aletoriamente 100 grãos e com isso obtido sua massa; Biomassa (BIO), em que foi pesado todas as plantas colhidas na parcela depois de seca, incluindo parte aérea juntamente com as vagens fechadas e a parte radicular.

Aos 60 e aos 90 dias depois da semeadura foi feito a coleta de raiz na linha e na entre linha de semeadura, calculando a densidade de raiz (Da) e profundidade efetiva (Ze). A coleta foi feita com auxílio de um trado até a profundidade de $0,4 \mathrm{~m}$, onde foram encontradas raízes, estratificando essa amostragem em camadas de $10 \mathrm{~cm}$. Foram feitas duas repetições em cada parcela de cada posição de coleta. A densidade de raiz (Da), em que foi obtido contabilizando massa de raiz colhida e fazendo a relação para o volume de amostra coletado, e profundidade radicular efetiva (Ze), através da distribuição de massa radicular entre camadas acumuladas, se

\section{RESULTADOS E DISCUSSÃO}

As temperaturas foram aumentando gradativamente entre os meses de julho e

A.

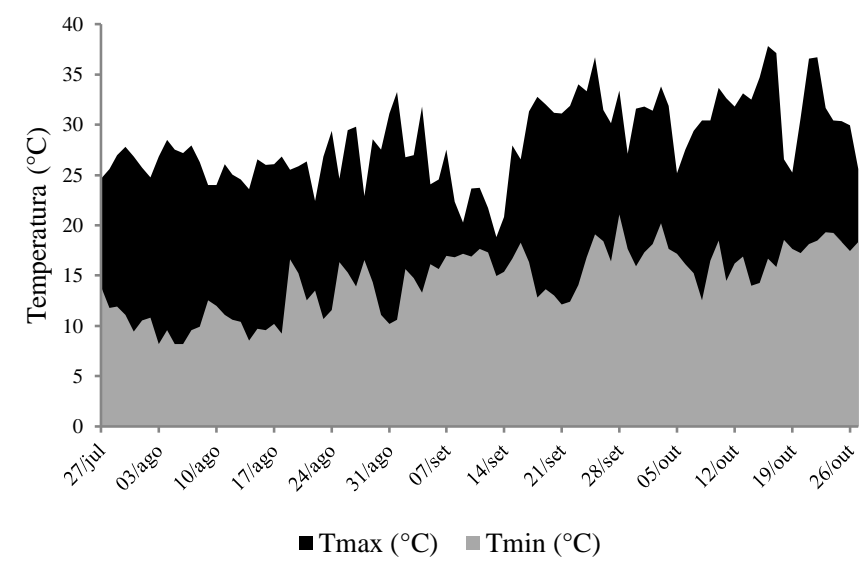

obteve profundidade até onde se concentrava $80 \%$ das raízes.

Avaliou-se também quatro tipos de índices de produtividade da água, o WP1 ${ }^{1}$ em que é estudada a relação de produtividade dos grãos e quantidade de água total aplicada; $\mathrm{WP}^{2}$, em que é avaliada a relação de biomassa no final do ciclo da cultura com o total de água aplicada; IWP, em que estuda a relação da produtividade de grãos e a água aplicada somente através da irrigação, tirando assim a quantidade de chuva ocorrida; e EWP, que é a relação da produtividade com a evapotranspiração da cultura (ALI; TALUKDER, 2008).

A análise de regressão comum foi elaborada considerando os efeitos linear e quadrático. Foi feito também análise de regressão segmentada considerando o efeito biológico, que é uma análise de regressão mais sensível, para estimar o nível de ótimo da lâmina de irrigação $\left(\mathrm{X}_{0}\right)$ em cada variável analisada (plateau) (KAPS; LAMBERSON, 2004), utilizando o procedimento PROC GLM e PROC NLIN, respectivamente, do SAS (SAS Institute, 2010, Versão 9.1.3).

outubro (Figura 2A). A radiação apresentou o mesmo comportamento (Figura 2B).

B.

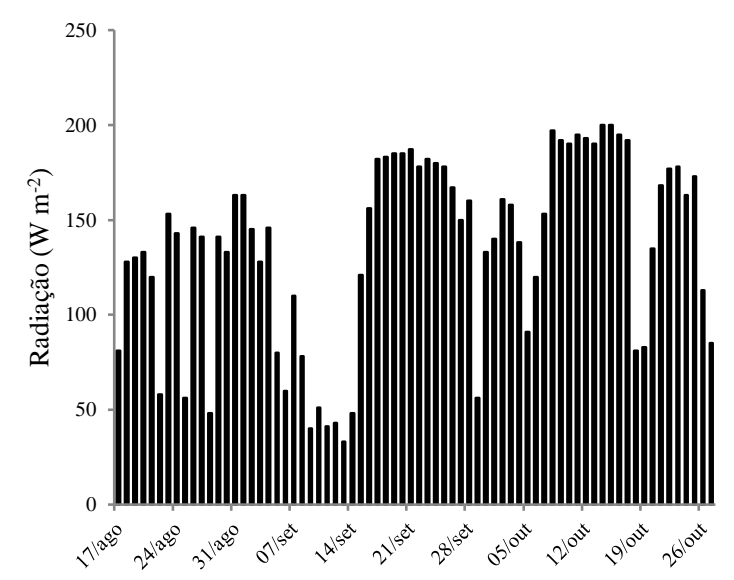

Figura 2. Temperatura máxima e mínima (A) e radiação (B) registrados durante o período de julho a outubro de 2015. 
A temperatura média para o mês de agosto, setembro e outubro de 2015 foram, respectivamente, $26,4,28,3$ e $31,4^{\circ} \mathrm{C}$; a mínima média, seguindo a mesma ordem, foi de 11,5, 15,8 e $17,1^{\circ} \mathrm{C}$; a radiação média para esse período foi de $120,3 \mathrm{~W} \mathrm{~m}^{-2}$ no mês de agosto,
$126,2 \mathrm{~W} \mathrm{~m}^{-2}$ em setembro e $157,8 \mathrm{~W} \mathrm{~m}^{-2}$ em outubro.

Foi possível observar que nos menores níveis de irrigação, a precipitação efetiva foi maior devido o solo apresentar menor teor de água (Tabela 1).

Tabela 1. Quantidade de lâmina aplicada, precipitação efetiva e não aproveitada pela cultura de acordo com cada tratamento.

\begin{tabular}{ccccc}
\hline $\begin{array}{c}\text { Níveis de } \\
\text { irrigação }\end{array}$ & $\begin{array}{c}\text { Lâmina de irrigação } \\
\text { aplicada }\end{array}$ & $\begin{array}{c}\text { Precipitação não } \\
\text { efetiva }\end{array}$ & $\begin{array}{c}\text { Precipitação } \\
\text { efetiva }\end{array}$ & $\begin{array}{c}\text { Total de água } \\
\text { aplicada }\end{array}$ \\
\hline $30 \%$ & 175,8 & 83,7 & 63,2 & 322,7 \\
$80 \%$ & 256,0 & 93,5 & 53,4 & 402,9 \\
$100 \%$ & 272,3 & 97,3 & 49,6 & 419,2 \\
$145 \%$ & 345,9 & 106,9 & 40,0 & 492,8 \\
\hline
\end{tabular}

Devido aos diferentes regimes de irrigação, o solo permanece mais úmido ou menos úmido de acordo com a quantidade de água que recebe. Com isso, a precipitação efetiva, ou seja, aquela que é infiltrada e está disponível na profundidade das raízes das plantas, difere de acordo com o regime de irrigação adotado. Como se nota na Tabela

A.

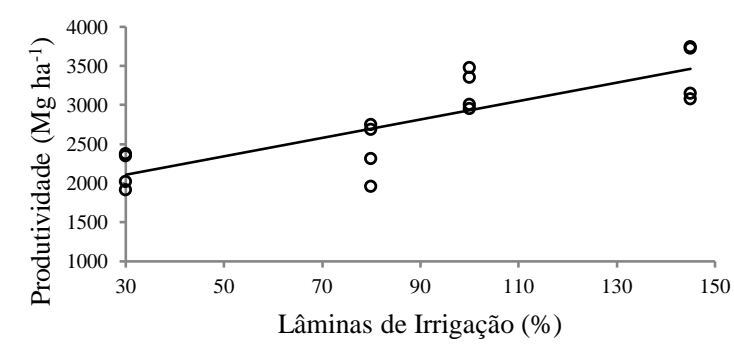

Prod $=11,63 \mathrm{LI}+1777,2$ $\mathrm{R}^{2}=0,85$

C.

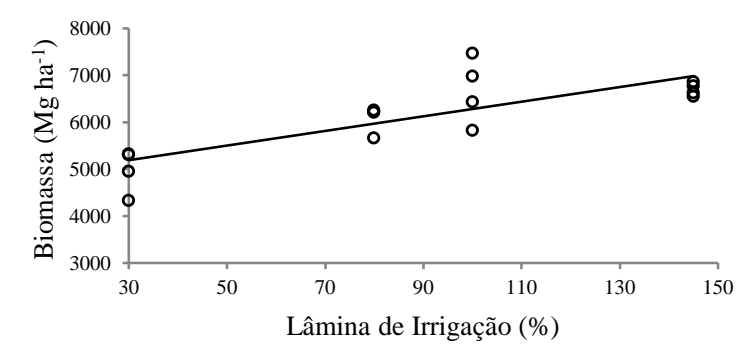

Bio $=15,42 \mathrm{LI}+4750,11$

$\mathrm{R}^{2}=0,84$
1, o tratamento que recebeu menor regime de irrigação apresentou maior precipitação efetiva, pois 0 solo se encontrava com menor teor de água do que os demais tratamentos.

Na Figura 3 foi apresentada a relação da regressão linear de cada parâmetro significativo para este tipo de regressão.

B.

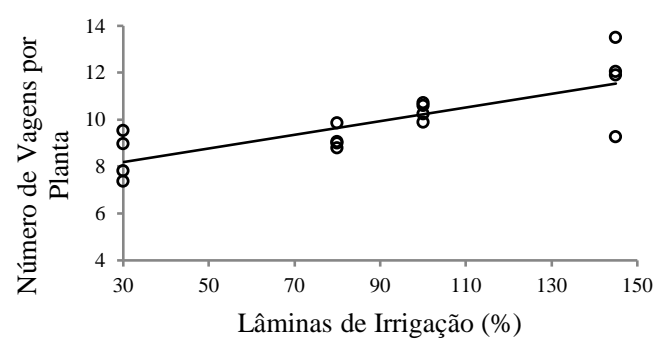

$$
\mathrm{NVP}=0,029 \mathrm{LI}+7,36
$$$$
\mathrm{R}^{2}=0,94
$$ 
Prod: produtividade, em kg ha ${ }^{-1}$; LI: lâmina de irrigação, em \%; NVP: número de vagens por planta; Bio: biomassa, em $\mathrm{kg} \mathrm{ha}^{-1}$.

Figura 3. Análise de regressão ente os tratamentos de lâmina de irrigação na produtividade (A), número de vagens por planta (B) e biomassa (C) com suas respectivas equações e $\mathrm{R}^{2}$.

De acordo com a análise de valores ótimos para as lâminas de irrigação regressão segmentada foi possível observar testadas (Tabela 2).

Tabela 2. Análise de regressão segmentada em cada variável analisada de acordo com o tipo de tratamento de adubação (TA), com seus valores de lâmina de irrigação, em porcentagem, representado por $\mathrm{X}_{0}$, e o valor ótimo, representado pelo plateau.

\begin{tabular}{lcc}
\hline Variável & $\mathrm{X}_{0}$ & Plateau \\
\hline Massa de 100 grãos (g) & 78 & 24,5 \\
Número de sementes por vagem & 58 & 6,4 \\
Biomassa $\left(\mathrm{kg} \mathrm{ha}^{-1}\right)$ & 138 & 6734,5 \\
$\mathrm{WP}^{2}\left(\mathrm{~kg} \mathrm{~mm}^{-1} \mathrm{ha}^{-1}\right)$ & 64 & 16,5 \\
$\mathrm{EWP}\left(\mathrm{kg} \mathrm{mm}^{-1} \mathrm{ha}^{-1}\right)$ & 143 & 13,2 \\
Densidade radicular $\left(\mathrm{g} \mathrm{cm}^{-3}\right)$ & 44 & 0,3 \\
Profundidade radicular efetiva $(\mathrm{cm})$ & 71 & 18,2 \\
\hline
\end{tabular}

A produtividade apresentou relação linear significativa para os níveis de irrigação (Figura 3A), sendo quanto maior a quantidade de lâmina de irrigação aplicada, maior a produtividade do feijoeiro.

O comportamento linear da produtividade de acordo com as lâminas leva à hipótese de que a ocorrência de temperaturas acima dos $30^{\circ} \mathrm{C}$ por um período no estádio de floração e formação das vagens possa ter influenciado. As parcelas que receberam maior quantidade de irrigação, como as do nível de irrigação de $145 \%$, podem não ter sofrido tanto com o calor excessivo por estarem com o solo constantemente muito úmido, tendo assim energia disponível para ser utilizada para as trocas de calor com a atmosfera. Enquanto que as outras parcelas, que receberam menor quantidade que a lâmina de $145 \%$ estava com o solo com menor teor de água, sentindo mais com a perda de calor, chegando assim a afetar o desempenho da planta, que nesse período se encontrava no estágio crucial para o desempenho final da produção de grãos.

Outra hipótese possível é a época em que o cultivo foi realizado. Devido a predominância de condições climáticas amenas, a demanda evapotranspirométrica através do método de cálculo adotado não foi tão elevado quanto seria se o cultivo fosse realizado na época do verão, por exemplo, não permitindo assim que a planta expressasse sua máxima demanda.

Alguns autores concordam com a relação apresentada. No trabalho de Andrade Júnior et al. (2002), obtiveram uma relação quadrática das lâminas aplicadas com a produtividade do feijão, obtendo um ponto ótimo através da equação de regressão de $387 \mathrm{~mm}$, sendo além disso prejudicial à produção, lâmina essa semelhante ao aplicado no tratamento com lâmina de $145 \%$.

O comportamento linear da produtividade com as lâminas de irrigação também foi observado por Blanco et al. (2011) com o feijão-caupi para condições climáticas do nordeste, onde aplicaram níveis crescentes de lâmina de irrigação até cerca de 550 $\mathrm{mm}$.

Esses valores de produtividade observados foram superiores aos encontrados por Binotti et al. (2007) e Andrade et al. (2005), sendo o primeiro experimento com cultivo de feijão no período seco e o outro na estação chuvosa. Richetti et al. (2011), obtiveram uma produtividade para feijão irrigado de $2400 \mathrm{~kg} \mathrm{ha-}$ ${ }^{1}$ para a região do centro oeste, valor observado no nível de irrigação de $100 \%$. 
Na variável de massa de 100 grãos foi possível observar um valor ótimo de $24,54 \mathrm{~g}$ a uma lâmina de irrigação de 78\% (Tabela 2), devido a regressão segmentada seguir o comportamento biológico, essa se torna uma análise de regressão mais sensível que a linear e a quadrática. Mas devido a componente não ter sido significativa para algum tipo de ajuste matemático observado na análise de hierarquia e aninhamento, esse valor não pode ser usado para alguma inferência.

No número de sementes por vagem (NSV) também não foi observado significância para algum tipo de modelo de regressão, no entanto, foi observado um plateau de 6,4 sementes (Tabela 2).

A baixa variação dos dados observada nos tratamentos e a não significância para algum tipo de ajuste matemático no NSV também foi observada no trabalho de Meira et al. (2005), com uma média de 5,43 sementes por vagem, e também por Sant'Ana et al. (2011).

O número de vagens por planta apresentou relação linear com as lâminas de irrigação (Figura 3B). Os dados apresentados por Crusciol et al. (2007) e Soratto et al. (2005) concordam com o número de vagens por planta obtido. Esses também observaram comportamento linear do NVP de acordo com o aumento dos níveis de lâmina de irrigação.

Na biomassa se obteve significância de 5\% para relação linear com os níveis de irrigação. Observou-se comportamento semelhante à produtividade, o que leva a deduzir que a produção de biomassa foi correspondente à produção de grãos.

Observou-se um valor ótimo de biomassa com uma concentração de quantidade de água irrigada de 138\%, o que pode resultar em 6734,5 $\mathrm{kg} \mathrm{ha}^{-1}$ (Tabela 2).

De acordo com Khan et al. (2010), a restrição de disponibilidade hídrica para a cultura reduz a produção de biomassa total, o que por sua vez compromete a capacidade da planta sustentar uma alta produtividade, principalmente se essa restrição acontecer em uma fase crucial dos estágios fenológicos, como ocorreu nesse trabalho, em que o estresse hídrico foi aplicado a partir do início da floração. Sob condições de sequeiro, conhecer o período de cultivo mais propício é essencial quando se tenta evitar que a cultura tenha resposta negativa ao estresse hídrico.

Wakrim et al. (2005) observaram uma diminuição do desempenho da cultura conforme havia menor disponibilidade de água, mas ao mesmo tempo a eficiência do uso da água apresentava aumento. Tendo em vista que o sistema radicular das plantas que vão estar sobre déficit hídrico, vai estar mais desenvolvido em profundidade devido à procura de água no solo, a cultura estará aproveitando melhor a disponibilidade de água que encontra ao longo do perfil.

De acordo com Ali; Talukder (2008), quando o estresse é posto de forma progressiva, a planta consegue se adaptar ao novo ambiente e com isso sua evapotranspiração não é seriamente afetada. Entretanto, quando se dá de forma contrária, repentinamente, o rendimento é afetado através da redução, principalmente, da taxa de evapotranspiração. Ou ainda, no caso do feijoeiro, há estágios em que a planta responde positivamente à restrição de água.

Segundo Geerts; Raes (2009) o estresse ao feijoeiro é benéfico quando aplicado na fase de maturação dos grãos, quando a vagem inicia seu processo de secagem no campo. Quando dado de forma estratégica pode melhorar o rendimento da cultura no campo, como observado por Gençoğlan et al. (2006), Hegab et al. (2014) e Satriani et al. (2015). Contribuindo com isso para melhoria dos índices de produtividade da água, que é o que se busca em períodos em que há restrição da disponibilidade de recursos hídricos.

Neste trabalho o estresse foi aplicado na fase de floração e enchimento dos grãos, porém não foi observada diferença significativa para regressão do IWP entre os tratamentos, obtendo uma média de 12,43 kg $\mathrm{mm}^{-1} \mathrm{ha}^{-1}$ geral entre os tratamentos. 
Também não houve efeito linear significativo para o $\mathrm{WP}^{1}$ e $\mathrm{WP}^{2}$. Observouse uma média para essas variáveis de, respectivamente, 7,45 e $16,34 \mathrm{~kg} \mathrm{~mm}^{-1}$ ha $^{-}$ 1. Mas com o EWP foi possível observar comportamento linear entre as lâminas de irrigação (Figura 4).

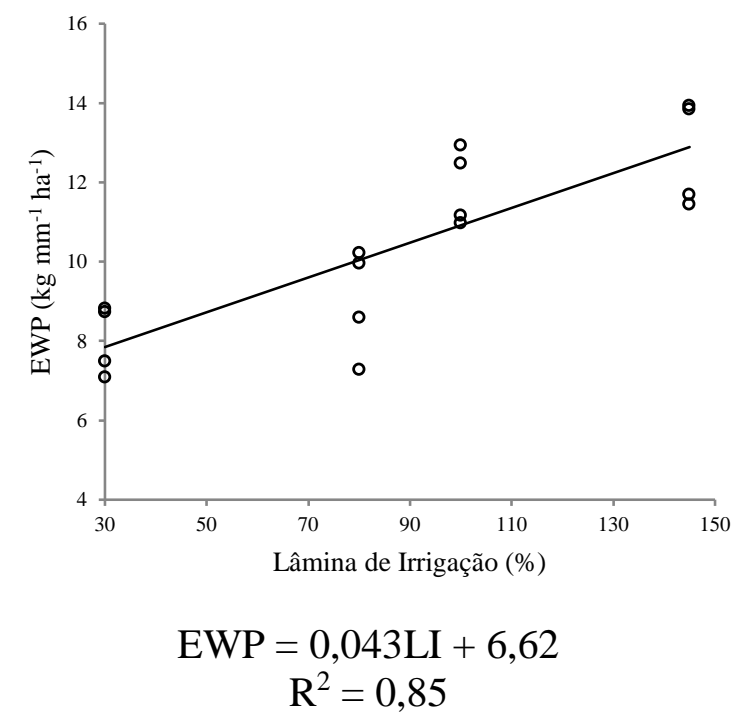

EWP: produtividade evapotranspirométrica, em kg $\mathrm{mm}^{-1} \mathrm{ha}^{-1}$; LI: lâmina de irrigação, em \%.

Figura 4. Análise de regressão no índice de produtividade da água evapotranspirada (EWP) com suas respectivas equações significativas e médias.

Como o EWP leva em consideração a evapotranspiração, esse vai interferir no aumento da ETc, o que consequentemente reflete no potencial produtivo da planta, pois quanto mais energia demandada pela atmosfera, uma planta bem suprida de água tem disponibilidade para enfrentar essa perda para o ambiente sem afetar o funcionamento do seu organismo, o que não compromete sua produção final em relação ao quesito de demanda hídrica. Havendo assim um indicativo de uma relação direta de evapotranspiração produtividade/rendimento, exercendo influência nas variáveis ligadas à produtividade da planta.

$\mathrm{Na}$ variável densidade de raiz não se observou algum tipo de relação linear ou quadrática. Mas ao mesmo tempo foi possível observar um plateau para concentrações mínimas de lâmina de irrigação (Tabela 2). Esse apresentou valor médio de $0,36 \mathrm{~g} \mathrm{~cm}^{-3}$. Um sistema radicular bem estruturado e em completa exploração do solo no seu entorno está diretamente relacionado a um bom desenvolvimento da planta.

Alves (2014) encontrou distribuição de raízes nas camadas no solo semelhante com observado nesse trabalho quando estudado comportamento de variáveis de feijão irrigado. No entanto, neste trabalho ele observou presença de raízes até $1,0 \mathrm{~m}$ de profundidade, contrastando com esse que só se observou até 0,40 m. Alsina et al. (2011) concordam com a atividade radicular observada em relação à disponibilidade hídrica.

Apesar de mais desenvolvida em termos de profundidade, as raízes das parcelas que sofreram restrição hídrica não contribuíram para uma maior produtividade.

Foi possível obter um plateau de $18,2 \mathrm{~cm}$ com uma lâmina de irrigação mínima de em torno de 70\% da ETc (Tabela 2).

Sousa et al. (2009) concordam com o apresentado, observando mesmo comportamento com o sistema radicular quando posto sobre situação de restrição hídrica.

\section{CONCLUSÕES}

Observou-se comportamento linear das lâminas de irrigação aplicada em relação às produtividades observadas e as demais variáveis que tiveram análise de regressão significativa. Portanto, com a cultivar de feijoeiro "Ouro Vermelho" foi obtido uma produtividade máxima de grãos de $3422 \mathrm{~kg} \mathrm{ha}^{-1}$ aplicando uma lâmina de irrigação de 346,0 mm mais 40 mm de precipitação efetiva.

\section{REFERÊNCIAS BIBLIOGRÁFICAS}

ALEXANDRATOS, N.; BRUINSMA, J. World Agriculture Towards 2030/2050, The 2012 Revision. Food and Agriculture Organization of the United Nations, 154p. 2012.

ALI, M. H.; TALUKDER, M. S. U. Increasing water productivity in crop production - A 
synthesis. Agricultural Water Management, 95, p. 1201-1213, 2008.

ALLEN, R. G.; PEREIRA, L. S.; RAES, D.; SMITH, M. Crop Evapotranspiration: Guidelines for computing crop water requirements. FAO Irrigation and Drainage Paper No. 56, FAO, Roma, 1998.

ALSINA, M. M.; SMART, D. R.; BAUERLE, T.; HERRALDE, F.; BIEL, C.; STOCKERT, C.; NEGRON, C.; SAVE, R. Seasonal changes of whole root system conductance by a droughttolerant grape root system. Journal of Experimental Botany, Oxford, v. 62, p. 99109, 2011.

ALVAREZ V.; V. H.; NOVAIS, R. F.; BARROS, N. F.; CANTARUTTI, R. B.; LOPES, A. S. Interpretação dos resultados das análises de solos. In: RIBEIRO, A. C.; GUIMARÃES, P. T. G.; ALVAREZ V., V. H. Recomendações para o uso de corretivos e fertilizantes em Minas Gerais $-\mathbf{5}^{\mathbf{a}}$ aproximação. 1 ed. UFV (Viçosa): UFV, 2015. Capítulo 5, p. 25-32.

ALVES, D. S. Aspectos produtivos e fisiológicos de cultivares de feijão irrigado. 2014. 88f. Tese (Doutor em Ciências)-Escola Superior de Agricultura Luiz de Queiroz, Universidade de São Paulo, Piracicaba, 2014.

ANDRADE, C. A. B.; FONTES, P. C. R.; CARNEIRO, J. E. S.; CARDOSO, A. A. Avaliação de critérios de recomendação de adubação sobre a produtividade de cultivares de feijão. Acta Scientiarum. Biological Sciences, v. 27, n. 2, p. 281-285, 2005.

ANDRADE JÚNIOR, A. S.; RODRIGUES, B. H. N.; FRIZZONE, J. A.; CARDOSO, M. J.; BASTOS, E. A.; MELO, F. B. Níveis de irrigação na cultura do feijão caupi. Revista Brasileira de Engenharia Agrícola e Ambiental, v, 6, n. 1, p. 17-20, 2002.

BERNARDO, S.; SOARES, A. A.; MANTOVANI, E. C. Manual de Irrigação. 8 ed. - Viçosa: Ed. UFV, 2006.
BINOTTI, F. F. S.; ARF, O.; ROMANINI JUNIOR, A.; FERNANDES, F. A.; SÁ. M. E.; BUZETTI, S. Manejo de solo e da adubação nitrogenada na cultura de feijão de inverno e irrigado. Bragantia, v. 66, n. 1, p. 121-129, 2007.

BIZARI, D. R.; MATSURA, E. E.; CHAMLET, J.; MESQUITA, M.; SALVADOR, C. A. Profundidade efetiva de raízes e sua relação com a parte aérea da cultura do feijoeiro irrigado em sistema de plantio direto. Revista Brasileira de Agricultura Irrigada, v. 4, n. 3, p. 172-183, 2010.

BORÉM, A.; CARNEIRO, J. E. S. A cultura. In: CARNEIRO, J. E.; PAULA JÚNIOR, T. J.; BORÉM, A. Feijão: do plantio a colheita. 1 ed. UFV (Viçosa): UFV, 2015. Capítulo 1, p. 9-15.

CHAGAS, J. M.; BRAGA, J. M.; VIEIRA, C.; SALGADO, L. T.; JUNQUEIRA NETO, A.; ARAÚJO, G. A. A.; ANDRADE, M. J. B.; LANA, R. M. Q.; RIBEIRO, A. C. Feijão. In: RIBEIRO, A. C.; GUIMARÃES, P. T. G.; ALVAREZ V., V. H. Recomendações para o uso de corretivos e fertilizantes em Minas Gerais $-5^{\mathbf{a}}$ aproximação. 1 ed. UFV (Viçosa): UFV, 1999. Capítulo 18.4.8, p. 306-307.

CRUSCIOL, C. A. C.; SORATTO, R. P.; SILVA, L. M.; LEMOS, L. B. Fontes e doses de nitrogênio para o feijoeiro em sucessão a gramíneas no sistema de plantio direto. Revista Brasileira de Ciência do Solo, 31, p. 15451552, 2007.

GEERTS, S.; RAES, D. Deficit irrigation as an on-farm strategy to maximize crop water productivity in dry areas. Agricultural Water Management, 96, p. 1275-1284, 2009.

GENÇOĞLAN, C.; ALTUNBEY, H.; GENÇOĞLAN, S. Response of green bean (P. vulgaris L.) to subsurface drip irrigation and partial rootzone-drying irrigation. Agricultural Water Management, 84, p. 274-280, 2006. 
HEGAB, A. S. A.; FAYED, M. T. B.; HAMADA, M. M. A.; ABDRABBO, M. A. A. Productivity and irrigation requirements of fababean in North Delta of Egypt in relation to planting dates. Annals of Agricultural Science, v. 59, n. 2, p. 185-193, 2014.

KAPS, M.; LAMBERSON, W. R. Biostatistics for Animal Science. CAB International, Wallingford, Oxfordshire, UK (2004), 459 p.

KHAN, H. R.; PAULL, J. G.; SIDDIQUE, K. H. M.; STODDARD, F. L. Faba bean breeding for drought-affected environments: a physiological and agronomic perspective. Field Crops Research, 115, p. 27-286, 2010.

Indicadores IBGE. Estatística da Produção Agrícola. Março de 2015. 73f.

MEIRA, F. A.; SÁ, M. E.; BUZETTI, S.; ARF, O. Doses e épocas de aplicação de nitrogênio no feijoeiro irrigado cultivado em plantio direto.

Pesquisa Agropecuária Brasileira, v. 40, n. 4, p. 383-388, 2005.

RENATO, N. S. Modelo de crescimento das culturas do milho e do feijão em condições de temperatura e $\mathrm{CO}_{2}$ atmosféricos elevados. 2013. 97f. Tese (Doutor em Meteorologia Agrícola)-Universidade Federal de Viçosa, Viçosa, 2013.

REZENDE, R.; FREITAS, P. S. L.; MANTOVANI, E. C.; FRIZZONE, J. A. Função de produção da cultura do milho e do feijão para diferentes lâminas e uniformidade de aplicação de água. Acta Scientiarum Agronomy, v. 26, n. 4, p. 503-511, 2004.

RICHETTI, A.; MELO, C. L. P.; SOUSA, J. P. B. Viabilidade econômica da cultura do feijão comum, safra 2012, em Mato Grosso do Sul. Comunicado Técnico 173, Embrapa, 2011.

SANT'ANA, E. V. P.; SANTOS, A. B.; SILVEIRA, P. M. Eficiência do uso de nitrogênio em cobertura pelo feijoeiro irrigado. Revista Brasileira de Engenharia Agrícola e Ambiental, v. 15, n. 5, p. 458-462, 2011.

SATRIANI, A.; LOPERTE, A.; SOLDOVIERI, F. Integrated geophysical techniques for sustainable management of water resource. A case study of local dry bean versus commercial common bean cultivars. Agricultural Water Management, 162, p. 57-66, 2015.

SILVA, L. C. Recomendações de cultivares de feijão-vermelho para o estado de Minas Gerais. 2005. 91f. Tese (Doutor em Fitotecnia)Universidade Federal de Viçosa, Viçosa, 2005.

SORATTO, R. P.; CRUSCIOL, C. A. C.; SILVA, L. M.; LEMOS, L. B. Aplicação tardia de nitrogênio no feijoeiro em sistema de plantio direto. Bragantia, v. 64, n. 2, p. 211-218, 2005.

SOUSA, M. A.; LIMA, M. D. B.; SIMON, G. A.; ANDRADE, J. W. S. Efeito do estresse hídrico na densidade do comprimento radicular em estádios do desenvolvimento do feijoeiro. Pesquisa Agropecuária Tropical, v. 39, n. 1, p. 25-30, 2009.

VAN GENUCHTEN, M. T. A closed form equation for predicting the hydraulic conductivity of unsaturated soils. Soil Science Society of America Journal, v. 44, p. 892-898, 1980.

WAKRIM, R.; WAHBI, S.; TAHI, H.; AGANCHICH, B.; SERRAJ, R. Comparative effects of partial root drying (PRD) and regulated déficit irrigation (RDI) on water relations and water use efficiency in common bean (Phaseolus vulgaris L.). Agriculture, Ecosystems \& Environment, 106, p. 275-287, 2005.

VIEIRA, C. Métodos culturais. Informe Agropecuário, v. 25, n. 223, p. 57-59, 2004. 